\title{
Networks for Africa
}

\section{The future of science and technology in Africa depends on the development of mutually supportive networks. Two examples show how imaginative initiatives can be turned into models for others.}

$\int^{\circ}$ outh Africa occupies a curious political position within its continent. The wealthiest of all the African nations, it inspires outsiders with the manner of its transition over the past 11 years from an apartheid-based regime towards a 'rainbow nation'. The vision of the African National Congress, as promoted so successfully by Nelson Mandela, is now being carried forward by his successors. But because of its past or its ability to prosper from the wealth and infrastructure built up by the apartheid regime, South Africa is sometimes viewed a little askance by other African nations, and its capacity to take a lead may be compromised.

But that is no reason for its initiatives to receive anything less than encouragement from other African countries, especially when they have the potential to be extended beyond its borders. And given that most donor support is directed at health and agriculture, indigenous initiatives that strengthen mathematical and physical sciences in the region are to be especially welcomed. Two in particular are worth celebrating and deserve further support.

\section{Star performers}

One example is the National Astrophysics and Space Science Programme. Its main aim is to make coherent use of a small and fragmented academic community distributed around South Africa's universities, to provide education and training. The scheme is based at the University of Cape Town and coordinated there, but all the universities involved take responsibility for developing and delivering courses and hosting students for research projects. Lecturers from other universities travel to Cape Town to give course modules. The other universities do not lose out, however - more than $50 \%$ of MSc students return to the partner institutions to complete their course, and any university can award the degree.

The approach was developed by the astronomy community itself and attracted support from the Ford and Andrew W. Mellon foundations. It is now rightly seen by the government as a model to be encouraged, and there is hope that South Africa's Department of Education will provide funds to support it and other similar schemes.

Importantly, the scheme has attracted students from other African countries. As accounts of its success feed back, so more students from those countries apply. One might hope that in any of these countries, several years from now, trained researchers returning from the scheme could have accumulated enough critical mass to set up centres in their own countries. The students are selected for their potential to do research - this is African capacity building in action. Other disciplines and other countries take note.

In a suburb of Cape Town is another example, also kick-started with the help of philanthropy: the African Institute for Mathematical Sciences (AIMS). The institute was launched in 2003 in what had been a dilapidated hotel, donated by the leading ANC member Ben Turok and his cosmologist son Neil, who now chairs its governing

body. Neil Turok's original proposal met much scepticism, but theoretical physicist Fritz Hahne, former dean of science at Stellenbosch University, saw the potential and became its director.

Fully residential, it accommodates some 40 graduate students from across Africa and is overflowing with academics from the developed world willing to give their time to come and teach them. There is an emphasis on applying mathematics to practical problem solving and learning to use back-of-the-envelope thinking to develop both analytical and computational approaches. Topics studied in more depth range from immunological and metabolic modelling to control theory, stochastic calculus and fundamental physics and cosmology. Vocational skills are also taught

"Although students initially have little in common, a pan-African feeling quickly develops." to introduce communication techniques for students, whose native languages include French and Arabic.

Most of the students on this year's course have moved on to South African universities to take postgraduate degrees, with about ten returning home. Although AIMS students initially have little in common, given the diversity of their countries and backgrounds, a pan-African feeling quickly develops, according to Hahne, and contacts with alumni have stayed strong.

AIMS costs about US $\$ 800,000$ a year, and hopes to expand to take in 70 students. It has drawn on philanthropic funds from the Mellon and Gatsby foundations and from Vodafone, and also on the commitment of those who give their time to work there - staff, students and visitors, including young African researchers.

\section{Future aims}

The operation's success has led to a proposal to set up 15 institutes across Africa over the next five years - not dones of AIMS but suitably tailored by those willing to take the lead in each case. This African Mathematical Institutes Network would hope to deliver 300 trained postgraduate mathematical scientists every year. The cost of establishing such a network could come to about $\$ 20$ million over the period.

This proposal depends for its implementation on the science and technology segment of the New Partnership for Africa's Development (NEPAD), set up in 2001 as an agency by which African states can channel development activities. NEPAD is set to be the key agency by which the G8 industrialized nations intend to fulfil their ambitions to increase assistance to Africa. NEPAD's "consolidated plan of action" for science and technology (www.nepadst.org/ publications/docs/doc27_082005.pdf) indudes several flagship projects in biotechnology, water, information technology and materials. A network fostering generically useful skills in mathematical sciences fully deserves to sit alongside them. 